\title{
Erratum to: The Gastric Tube
}

\author{
Gabriel O. Ionescu, Simona Gavrilescu, and Gabriel Aprodu
}

\section{Erratum to: \\ Chapter 29 in: H. Till et al. (eds.), Esophageal and Gastric Disorders in Infancy and Childhood, DOI 10.1007/978-3-642-11202-7_29}

Affiliation of authors Gabriel O. Ionescu, Simona Gavrilescu, and Gabriel Aprodu was incorrect and it should be:

Department of Pediatric Surgery,

University Children Hospital "St. Marry", Iasi, Romania

The updated original online version for this chapter can be found at DOI 10.1007/978-3-642-11202-7_29

G.O. Ionescu, $\mathrm{MD}, \mathrm{PhD}(*) \cdot \mathrm{S}$. Gavrilescu,

$\mathrm{MD}, \mathrm{PhD} \bullet \mathrm{G}$. Aprodu, $\mathrm{MD}, \mathrm{PhD}$

Department of Pediatric Surgery, University Children

Hospital "St. Marry", Iasi, Romania

e-mail:khank@email.arizona.edu 